\title{
Corrigendum
}

\section{Corrigendum to "Distribution and Bioaccumulation of Perfluoroalkyl Acids in Xiamen Coastal Waters"}

\author{
Journal of Chemistry \\ Correspondence should be addressed to Journal of Chemistry; jchem@hindawi.com \\ Received 10 January 2022; Accepted 10 January 2022; Published 28 February 2022 \\ Copyright (c) 2022 Journal of Chemistry. This is an open access article distributed under the Creative Commons Attribution \\ License, which permits unrestricted use, distribution, and reproduction in any medium, provided the original work is \\ properly cited.
}

In the article titled "Distribution and Bioaccumulation of Perfluoroalkyl Acids in Xiamen Coastal Waters" [1], there is an error in the first sentence of the Abstract section, where "harmless" should be corrected to "harmful" as follows: "Since perfluoroalkyl acids (PFAs) are widely used and harmless to organisms, they have attracted great attention in recent years" to "Since perfluoroalkyl acids (PFAs) are widely used and harmful to organisms, they have attracted great attention in recent years."

\section{References}

[1] Z. Dai and F. Zeng, "Distribution and bioaccumulation of perfluoroalkyl acids in Xiamen coastal waters," Journal of Chemistry, vol. 2019, Article ID 2612853, 8 pages, 2019. 